\title{
TRAUMATIC SHOCK. XV. CARBOHYDRATE METABOLISM IN HEMORRHAGIC SHOCK IN THE DOG ${ }^{1}$
}

\author{
By ARNOLD M. SELIGMAN, HOWARD A. FRANK, BENJAMIN ALEXANDER \\ AND JACOB FINE \\ (From the Surgical and Medical Research Departments, Beth Israel Hospital, Boston, and the \\ Departments of Surgery and Medicine, Harvard Medical School, Boston)
}

(Received for publication January 1, 1947)

Traumatic shock may be regarded as a process of rapid biologic.disintegration resulting from progressive tissue anoxia consequent to peripheral circulatory failure. This concept explains the recent growth of interest in the intermediary metabolic derangements in shock, which have been found to be severe, involving many enzyme systems concerned with protein and carbohydrate metabolism. Since the liver is a master organ in this respect, it deserves close scrutiny. That this organ should suffer at least as severely as any organ in shock is suggested by the sharp reduction in volume and velocity of flow through the portal system $(1,2)$ and by the observed reduction of liver excretory functions early in shock (3). Moreover, the recent demonstration that crosscirculation of the dog in hemorrhagic shock from a donor dog via the liver is capable of preventing the onset of irreversibility to transfusion (4) and of curing such irreversibility when established (5) indicates that liver damage plays a primary role in the shock phenomenon. It is, therefore, natural that a relationship should be sought between metabolic derangements in large part normally under liver control and the progressive deterioration characteristic of the late stages of the shock syndrome when therapy is no longer effective.

The metabolism of pyruvic and lactic acids and glucose shows abnormalities in shock $(6,7)$. In shock the rise in blood pyruvic acid and the simultaneous and usually disproportionately greater rise in lactic acid, producing an increase in the lactic to pyruvic acid ratio, are due to anoxia. Even though changes in blood concentration of these metabolites are not specific manifestations of traumatic shock, since they occur also in fever, following vigorous exercise, epinephrin injection, and in

1 The work described in this paper was done under a contract, recommended by the Committee on Medical Research, between the Office of Scientific Research and Development and Harvard University. other conditions, a change in the $L / P$ ratio is considered evidence of an abnormal carbohydrate metabolism as, for example, in thiamine deficiency (8). It was considered necessary to explore the possible relationship between spontaneous and induced shifts in the blood concentration of these substances and the progressive deterioration in hemorrhagic shock leading to the development of irreversibility to transfusion.

This communication reports the results obtained from a study of tolerance curves of glucose, lactic and pyruvic acids administered intravenously in various stages of hemorrhagic shock, both before and after transfusion.

\section{METHOD}

Irreversible hemorrhagic shock was produced in morphinized dogs by a technic described elsewhere (4). The injection of compounds was followed by arterial blood sampling every 15 minutes for 1 hour thereafter. Tolerance curves were obtained before hemorrhage, during hemorrhagic shock at a constant blood pressure of $30 \mathrm{~mm}$. $\mathbf{H g}$, and after transfusion of all shed blood. Pyruvic acid ${ }^{2}$ (Merck) was given as the sodium salt (neutralized to phenolphthalein) in doses of 0.5 to 1 gram for each tolerance test. Lactic acid (Merck, 85 per cent pure) was given as the sodium salt (neutralized to phenolphthalein) in 1-gram doses.

Blood pyruvic acid was determined by the method of Bueding and Wortis (9), blood lactic acid by the method of Barker and Summerson (10), total amino acid nitrogen by the colorimetric method of Frame, Russell, and Wilhelmi (11). Blood glucose was determined by the method of Folin (12).

\section{RESULTS}

1. Blood levels of lactic, pyruvic, and total amino acids in hemorrhagic shock

A. In 4 dogs (M-22, 23, 27, 28) there was a progressive rise in blood concentration of all 3 acids before therapeutic transfusion. The rise in lactic acid was steeper than that in pyruvic acid

2 The pyruvic acid was distilled within 1 week prior to the time of injection. 
with a resulting 2- to 4-fold elevation of the lactic/pyruvic acid ratio. Figures 1 and 2 give the data for dogs $M-23$ and $M-27$, which are typical.

B. In the same 4 dogs after therapeutic transfusion, which was ineffective for survival, the lactic acid level fell proportionately more than the pyruvic acid level, with a return of the $L / P$ ratio to near normal. The amino acid level did not change. In dog $\mathrm{M}-27$, observed for 5 hours after transfusion, a secondary rise in lactic and amino acid occurred after the blood pressure had again fallen below $60 \mathrm{~mm}$. $\mathrm{Hg}$.

\section{Lactic and pyruvic acid blood levels following} epinephrin injection in normal dogs

A continuous intravenous injection of epinephrin hydrochloride ( $3 \mathrm{mgm}$. per $\mathrm{kgm}$. per $\mathrm{min}$.) in a volume of 2 to $4 \mathrm{ml}$. of 0.85 per cent sodium chlo- ride solution was performed in 3 normal dogs (M-15, 38, 39). The lactic and pyruvic acid levels rose promptly in all 3 dogs and the $L / P$ ratio rose in 2 dogs. The lactic acid concentration leveled off after one hour in 2 dogs, but continued to rise in the third dog (M-38), which went into shock during the injection ( 2 hours) and died 15 minutes after discontinuance of the intravenous drip. In 2 of 3 dogs, elevation of the blood glucose level was followed by a fall to below the initial concentration during the second and third hours. The third dog ( $M-15)$ maintained an elevated blood glucose level throughout the experiment which lasted 3 hours. All dogs showed systolic blood pressure levels of about $200 \mathrm{~mm}$. $\mathrm{Hg}$ during the epinephrin drip. Dog M-15 survived; dog M-39 (Figure 3), whose systolic blood pressure was $100 \mathrm{~mm}$. $\mathrm{Hg}$ after discontinuance of the injection, died 12 hours later.

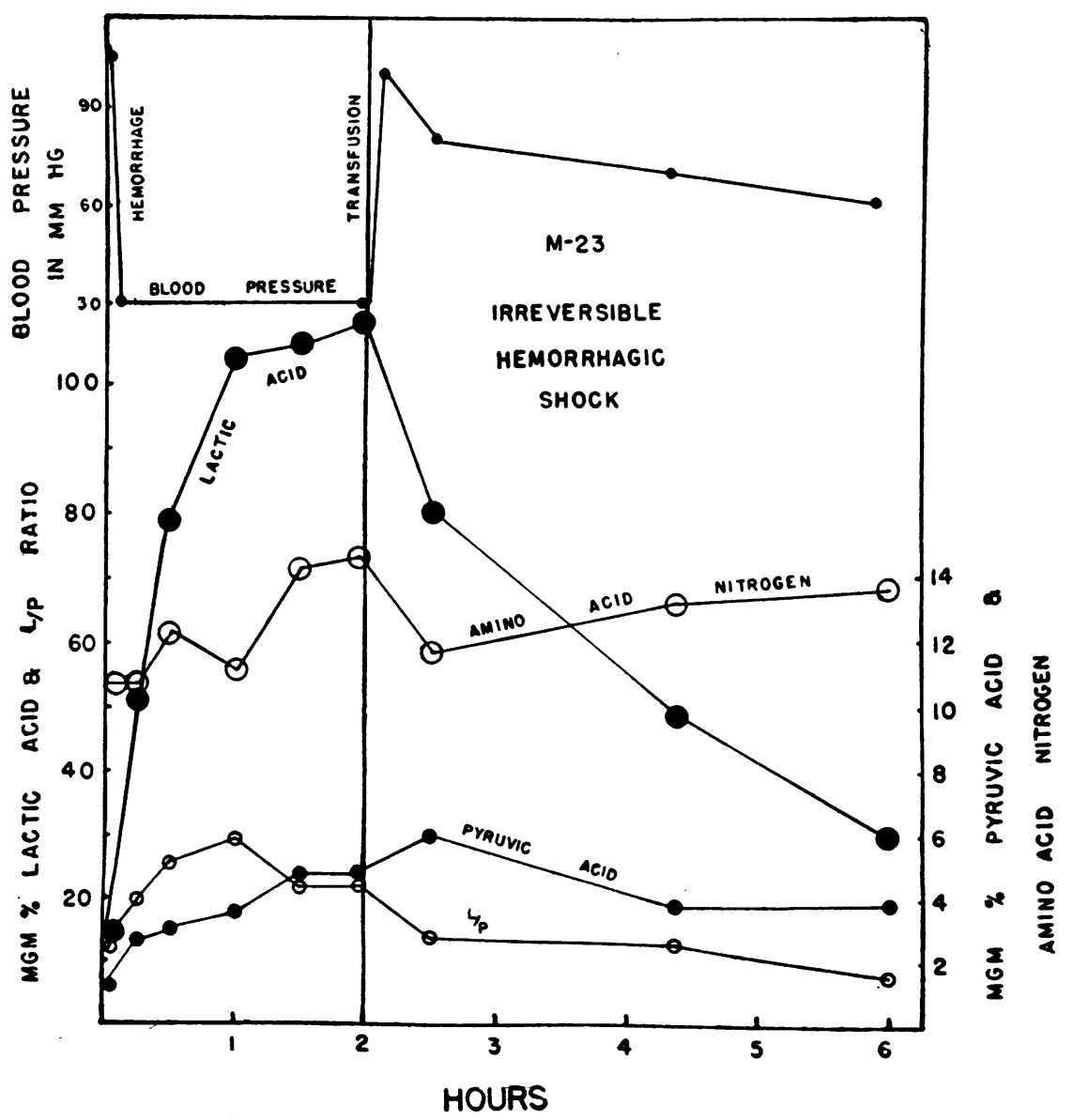

FIG. 1. 


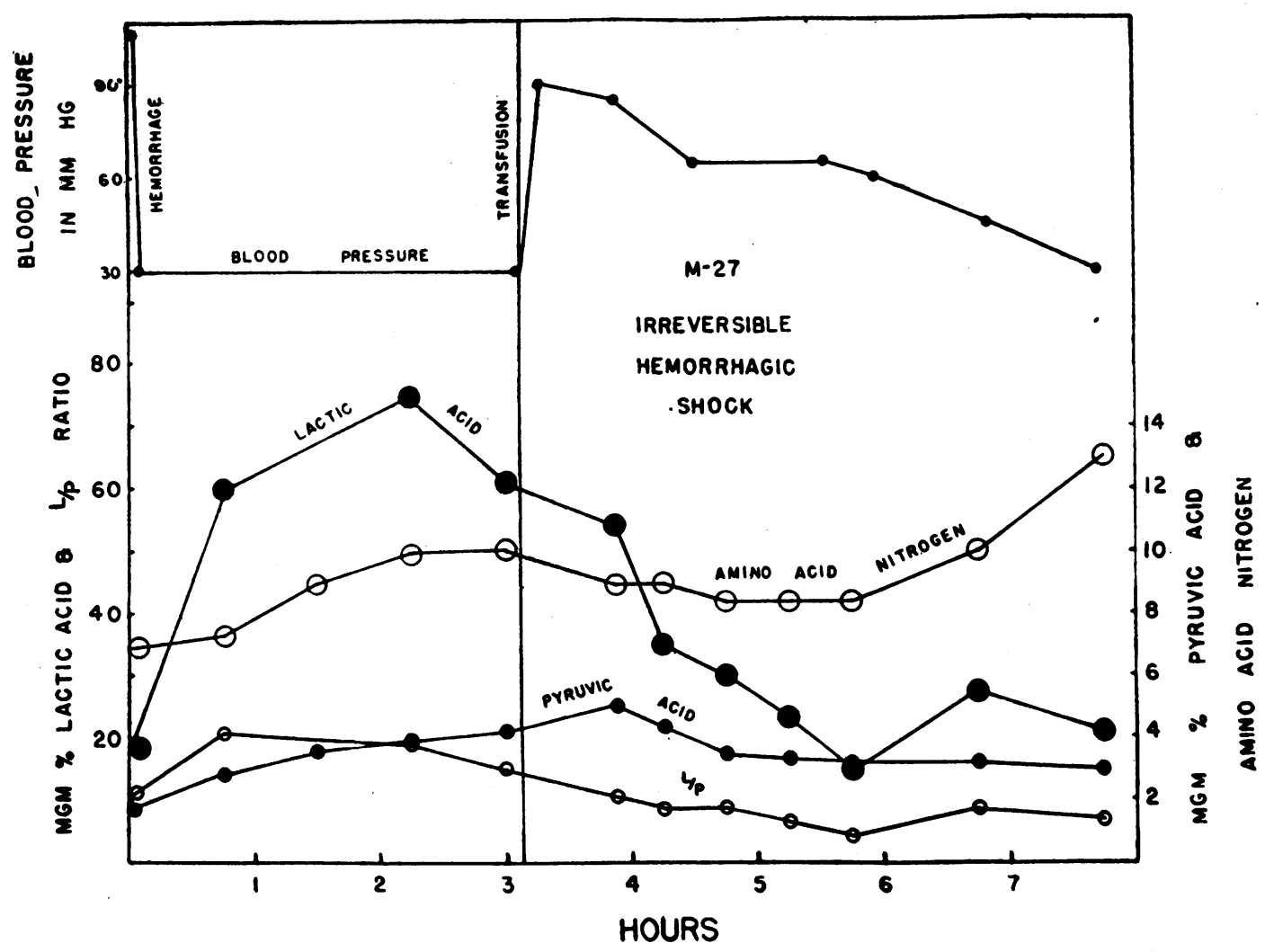

FIG. 2.

The changes in blood lactic and pyruvic acids in these experiments were not unlike those observed during vigorous exercise (8), but of a lower order of magnitude than was observed in hemorrhagic shock.

Comment: The changes in blood lactic and pyruvic acids in shock, therefore, are not referable entirely to epinephrin secretion or to the blood pressure level.

3. Blood levels of lactic and pyruvic acids in hemorrhagic shock in adrenalectomized dogs

To determine the relationship of the blood levels of these acids in shock to total adrenal secretion, unilateral adrenalectomy was followed in 2 weeks by removal (under local anesthesia) of the second adrenal. Immediately thereafter hemorrhagic shock was induced. Poor tolerance to hemorrhage and poor response to transfusion were observed. In 5 dogs (M-36, 37, 40, 41, 42) so studied (Figure 4, M-36) though the blood glucose fell, prompt rises in lactic and pyruvic acid and in the $L / P$ ratio similar to those noted above (Section 1) were observed. The lactic and pyruvic acid levels remained elevated after transfusion.

Comment: These changes in shock, therefore, cannot be attributed to epinephrin or cortical hormone secretion. It also appears that they bear no relationship to the level of blood glucose.

\section{In vitro experiments}

To determine to what extent the observed shifts in lactic and pyruvic acids may reflect intravascular changes apart from those due to the activity of tissues other than blood, in vitro experiments were made as follows: $650 \mathrm{mgm}$. of glucose were added to $260 \mathrm{ml}$. of sterile arterial heparinized blood drawn under oil, with a resulting rise in glucose concentration from $70 \mathrm{mgm}$. per cent to $330 \mathrm{mgm}$. per cent. The blood was kept at $37.5^{\circ}$ C. under oil for 2 hours and sampled at 20-minute intervals. It took on the color of venous blood during the period of observation. The glucose concentration remained unchanged but the $\mathrm{L} / \mathrm{P}$ 


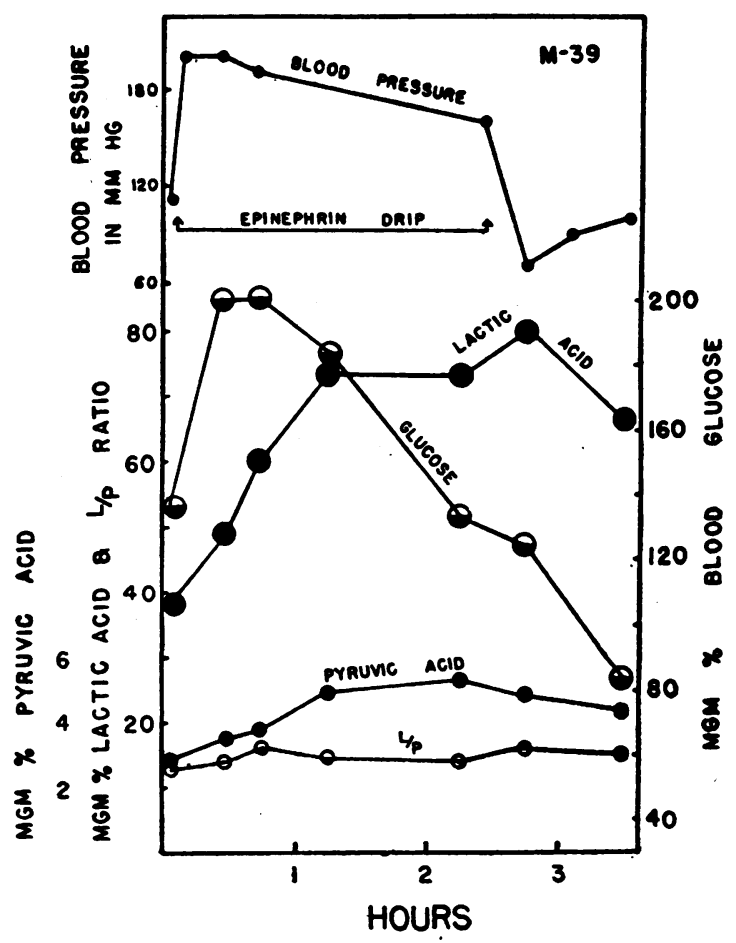

FIG. 3.

ratio rose slightly, though significantly, in 2 hours, in part at least because of a fall in the pyruvic acid, a phenomenon not observed in shock. The

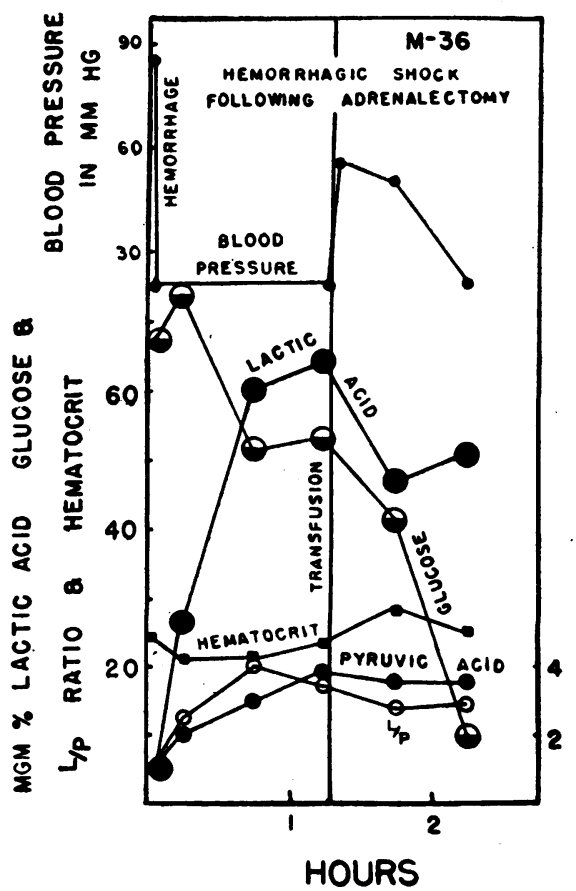

FIG. 4.

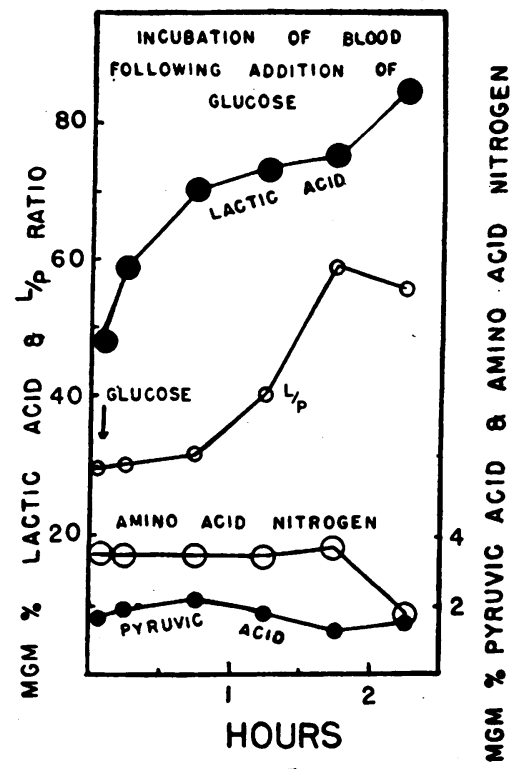

FIG. 5.

changes in lactic acid, pyruvic acid, and amino acid concentration are shown in Figure 5.

One hundred fifteen mgm. pyruvic acid neutralized with $\mathrm{NaOH}$ was added to $300 \mathrm{ml}$. arterial heparinized blood drawn under oil and kept at $37.5^{\circ} \mathrm{C}$. The pyruvic acid concentration rose from $4.8 \mathrm{mgm}$. to $32 \mathrm{mgm}$. per cent immediately following the addition of pyruvic acid and dropped to $30 \mathrm{mgm}$. per cent in $\mathbf{1 . 5}$ hours. There was a concomitant rise in lactic acid, presumably derived

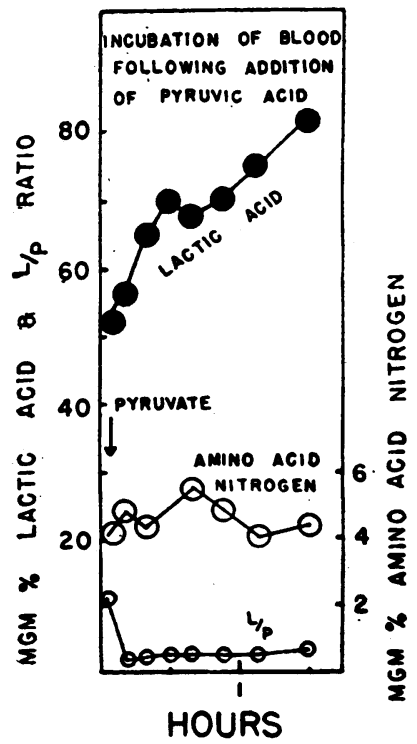

FIG. 6. 
from the added pyruvate through the action of the red cells, Figure 6.

Comment: These observations indicate that a decline in blood oxygen content per se does not account for any substantial fraction of the rise in the blood lactic acid in shock.

\section{Glucose tolerance curves in hemorrhagic shock}

Seven dogs $(M-16,29,30,33,34,47,48)$, in which irreversible hemorrhagic shock was produced, were given 1 gram per kgm. of glucose intravenously before hemorrhage, again during shock, and again following transfusion. Glucose, lactic and pyruvic acid levels in arterial blood were determined at 15-minute intervals after each injection.

The disappearance of injected glucose from the blood in 4 normal dogs required more than 1 hour. The disappearance rate during hemorrhagic shock was prolonged, but following transfusion it was near normal, whether the subsequent decline in blood pressure was precipitous or gradual.
Comment: The lactic and pyruvic acid levels characteristic of shock appeared not to be influenced by the injection of glucose (Figure 7).

\section{Lactic acid tolerance curves in hemorrhagic} shock

Sodium lactate, injected into normal dogs, increased the blood lactic acid concentration from 10 to $30 \mathrm{mgm}$. per cent at the peak of the rise. The lactate was usually, but not always, completely cleared. In one experiment the arterial blood $\mathrm{pH}$ was lowered from 7.4 to 7.2 (glass electrode). No significant alteration in blood pyruvic acid occurred.

Following the injection of lactate in hemorrhagic shock (Figure 8, M-19), the resulting superimposed rise in the blood lactic acid level was no greater than that following the injection of lactate in the normal dog. The shocked animal was able to clear the blood of injected lactate about as well as the normal dog.

Following transfusion, injected lactate was cleared from the blood at a normal or greater than

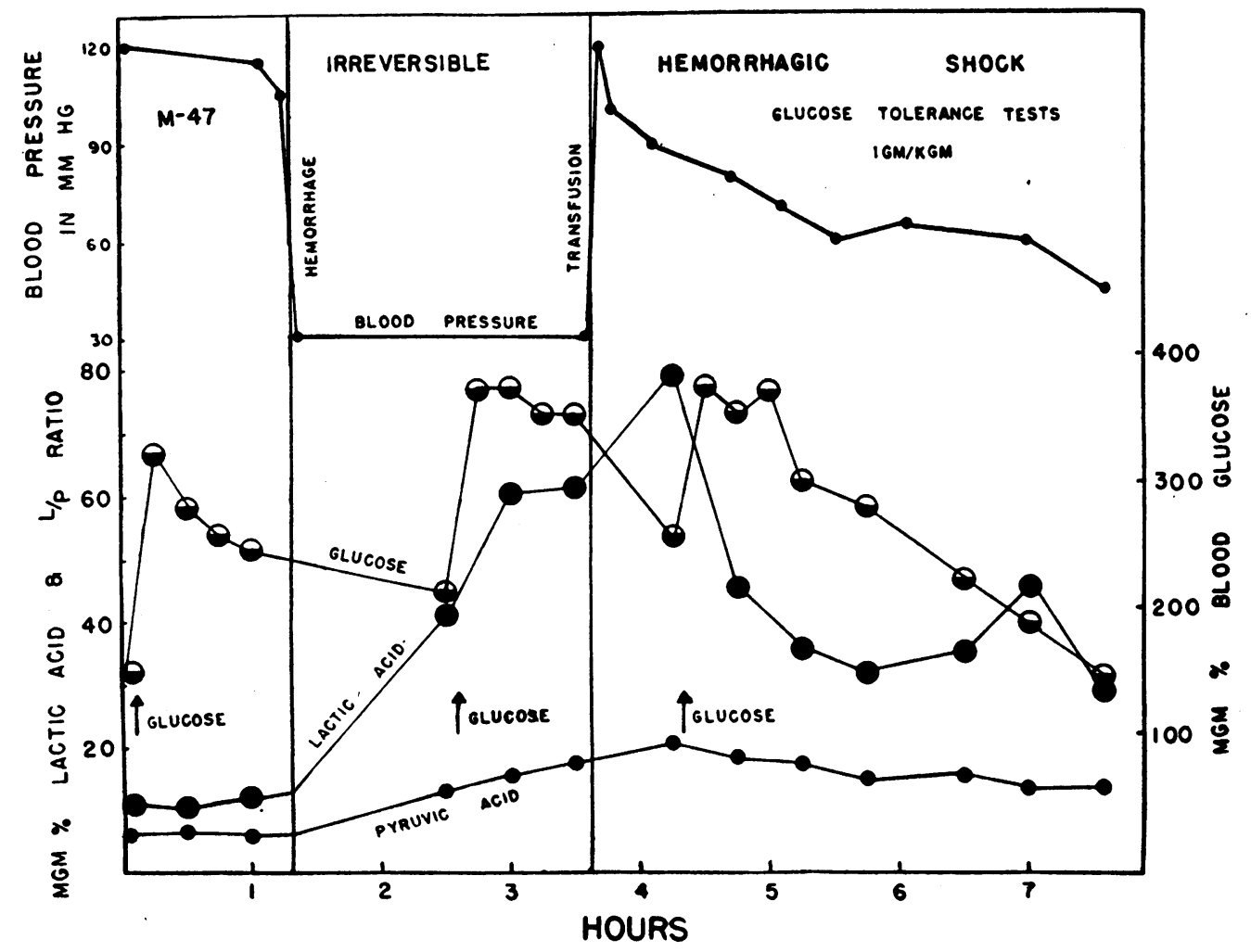

FIG. 7. 


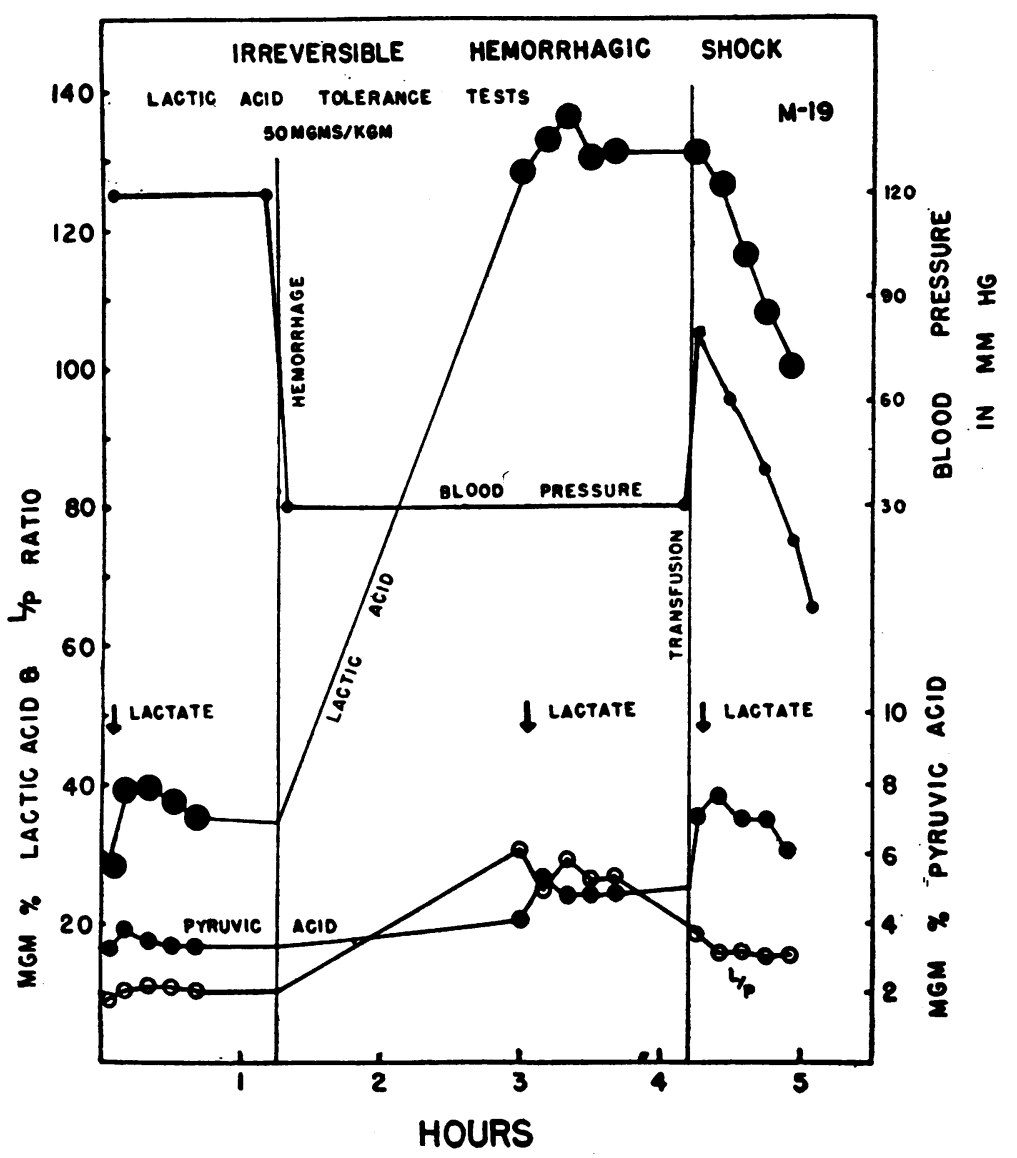

FIG. 8.

normal rate. In one experiment (Figure 8, M-19) the expected fall in blood lactic acid level was so rapid as to mask completely the increase due to injected lactate, even though a transfusion was ineffective and was followed by a rapid decline in blood pressure.

Comment: Since injected lactate is cleared from the blood in hemorrhagic shock at a normal rate even when the animal is dying after an ineffective transfusion, the deterioration of the organism in shock cannot be accounted for by the failure of enzyme systems to catabolize this carbohydrate intermediate. The foregoing data also suggest that an increase in the rate of lactic acid production is not the sole determinant of the level achieved. An alteration in the equilibrium between lactate and pyruvate or other carbohydrate intermediates may exist and be due in part to impairment of volume and velocity of blood flow rather than to damage to enzyme systems.

\section{Lactic acid tolerance in acidosis}

To learn whether the concentrations of lactic and pyruvic acids are determined by acidosis prevailing in shock, 1-gram doses of neutralized lactic acid were injected intravenously into normal dogs before and after the production of acidosis by intravenous hydrochloric acid. In one $\operatorname{dog}(\mathrm{M}-53$, Figure 9) the lactic acid tolerance curve following the injection of 1 gram of lactate was the same before and 10 minutes after the injection of $25 \mathrm{ml}$. of a 10 per cent solution of hydrochloric acid.

In another $\operatorname{dog}(\mathrm{M}-52), 1$ gram of lactate raised the arterial $\mathrm{pH}$ from 7.4 to 7.6 . In the course of 30 minutes, $250 \mathrm{ml}$. of $0.1 \mathrm{~N} \mathrm{HCl}$ were then injected. During the injection the blood pressure dropped to $70 \mathrm{~mm}$. $\mathrm{Hg}$, then to $30 \mathrm{~mm}$. $\mathrm{Hg}$ and the arterial blood $\mathrm{pH}$ dropped to 7.2, but the blood lactic acid rose only $10 \mathrm{mgm}$. per cent. Death occurred a few minutes later. In this experiment 


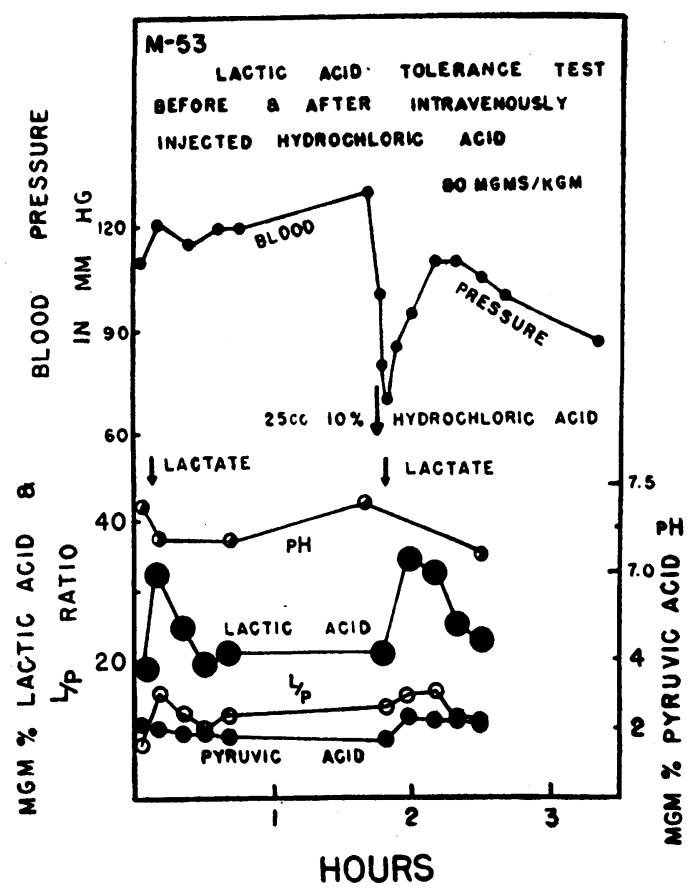

FIG. 9.

acidosis more severe in degree than occurs in hemorrhagic shock did not produce so great an elevation of the blood lactic acid level as is found in shock.

In a third dog (M-51, Figure 10) repeated injections of $1 \mathrm{~N}$ hydrochloric acid caused a steady fall in the $\mathrm{CO}_{2}$ combining power of the blood and in arterial blood $\mathrm{pH}$. At the same time there was a steady rise in blood lactic acid, while pyruvic acid changed very little. Though the $\mathrm{L} / \mathrm{P}$ ratio rose, it remained within normal limits. During this time the injection of 0.5 gram of lactate produced a normal tolerance curve (superimposed on the steadily rising blood lactic acid level) similar to that observed in hemorrhagic shock (Figure 8). The dog developed circulatory collapse and died when acidosis became severe.

Comment: It appears that the dog in acidosis metabolizes lactic acid as well as the normal or shocked animal. The rise in the blood levels of pyruvate and lactate (see Figures 9 and 10), following the production of a severe grade of acidosis; is not of the magnitude observed in hemorrhagic shock. The changes in these acids seen in hemorrhagic shock are not determined by the concurrent acidosis.

\section{Pyruvic acid tolerance in normal dogs}

Following the injection of pyruvic acid ( 0.05 to 0.1 gram per kgm. dog) neutralized to phenolphthalein, the return to the basal value occurred within 45 minutes in 13 of 17 normal dogs. The original level was not reached in this time in 4 dogs. The increase following the injection of pyruvate varied from 0 to $1.0 \mathrm{mgm}$. per cent. Concomitant lactic acid determinations showed very slight rises or no effect, but drops in lactic acid of 5 to $10 \mathrm{mgm}$. per cent below the starting level were noted in nearly each case at the end of 45 minutes (Figure 11). In 6 of 9 dogs the amino acid nitrogen was also depressed 2 or more mgm. per cent 45 minutes after the injection of pyruvic acid in 6 of 9 dogs.

9. Pyruvic acid tolerance in hemorrhagic shock cured by transfusion

In 4 of 7 dogs cured of hemorrhagic shock by transfusion, the pyruvic acid tolerance curves were the same before and after transfusion as in the nor-

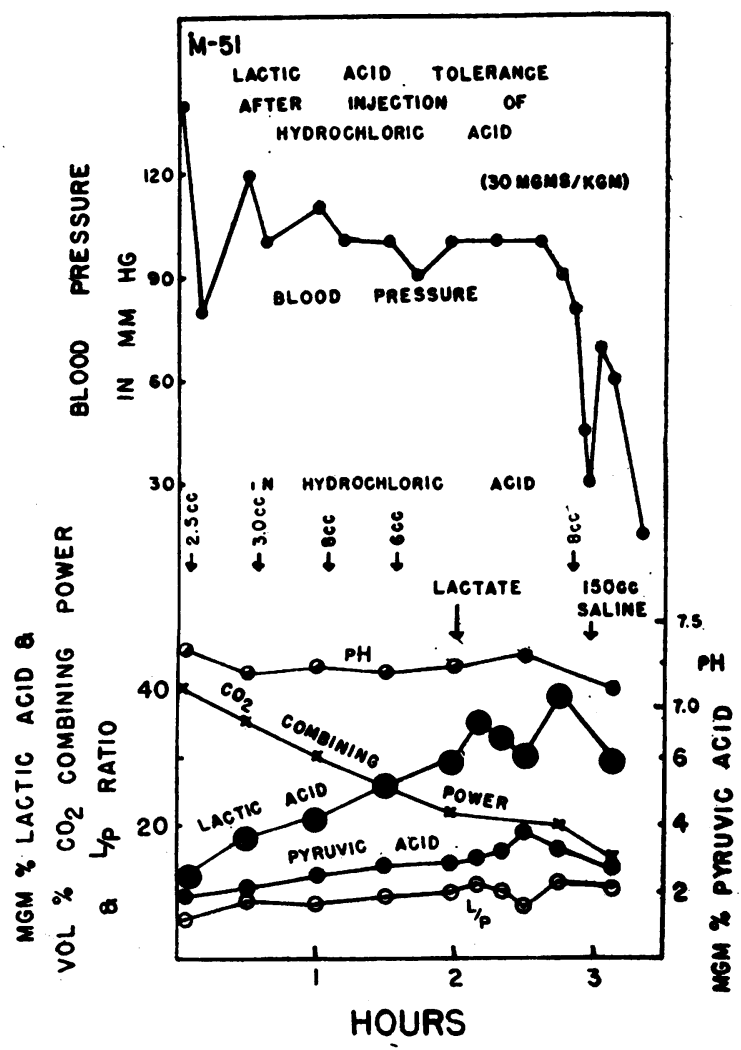

FIG. 10. 


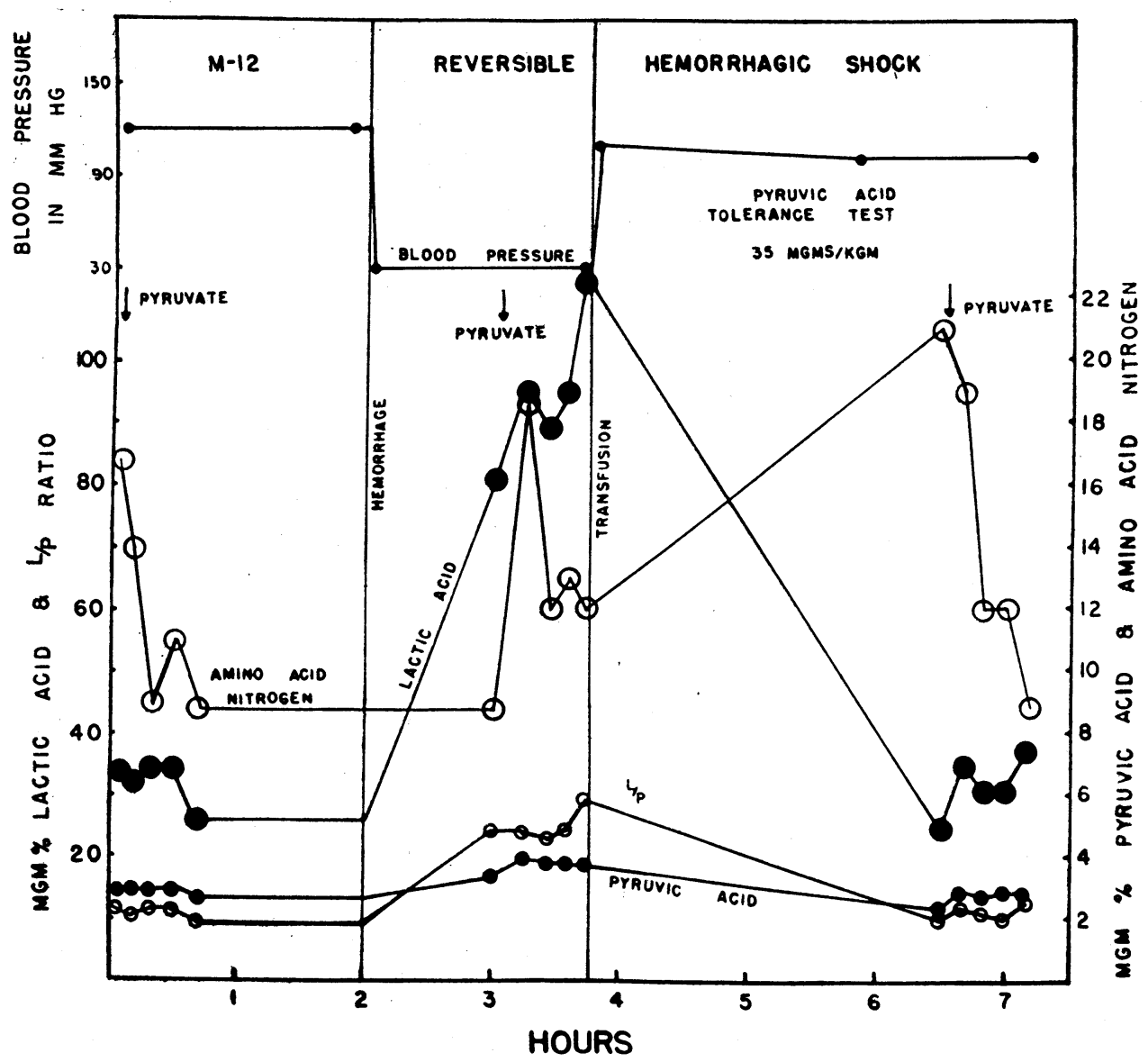

FIG. 11.

mal or preshock stage, although the preinjection levels of bloods pyruvate were higher during the shock state than before shock was instituted. In the remaining 3 dogs the last point of the tolerance curves during shock before and after transfusion were slightly higher than the preinjection level (Figure 11). The maximum rise in pyruvic acid during shock was in some instances slightly higher than in the normal. In some experiments evidence of lactic acid production from injected pyruvate during shock was suggested by the rapid rises in lactic acid levels immediately after the injection of pyruvate. Subsequent depressions in amino acid levels were observed. The usual rise in the $\mathrm{L} / \mathrm{P}$ ratio during shock and its return toward normal following transfusion was in no way altered by pyruvate injections.

Comment: Elevation of the pyruvic acid level in shock is not due to inability of the organism to clear the blood of pyruvic acid. The significance of the drop in amino acid nitrogen following pyruvate injection will be discussed in a subsequent publication.

10. Pyruvic acid tolerance in hemorrhagic shock not remediable by transfusion

Similar results were obtained in 3 of 9 dogs in hemorrhagic shock which did not respond to transfusion (M-9, Figure 12). In 5 dogs, a somewhat poorer clearance occurred during shock than in the normal or in the post-transfusion stage. One dog (M-21) showed very poor clearance before and after transfusion as compared to the normal. Although this dog received twice the usual dose of pyruvate, 2 others which received the double dose showed only a slightly poorer clearance in the shock stage than in the normal. The injection of pyruvate in these doses was followed in some cases by drops in blood pressure. One normal dog not included in the series went 


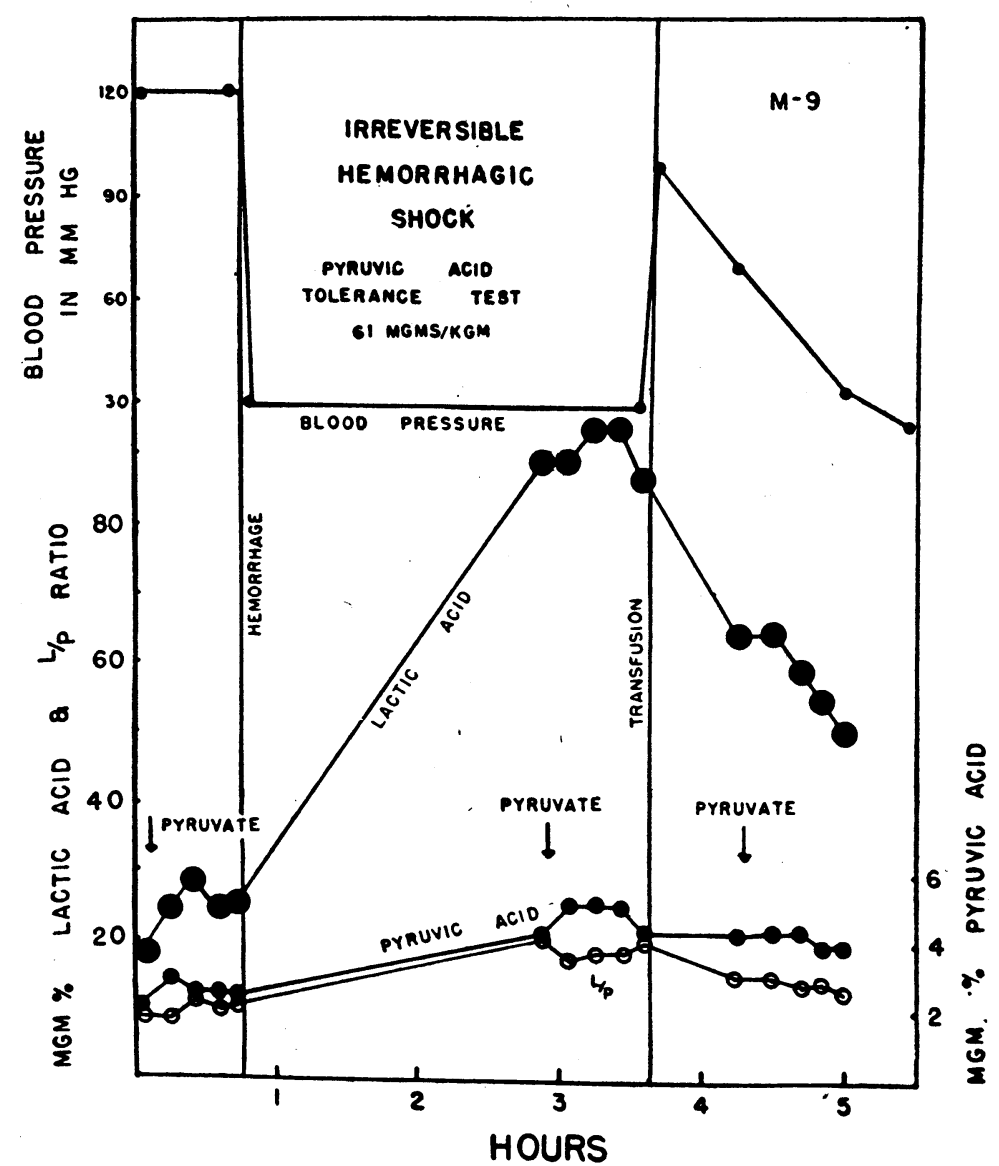

FIG. 12.

into shock for a considerable time following the injection of a double dose. Figure 12 shows that the rise of lactic acid during shock and the fall following transfusion are not altered by the injection of pyruvic acid. Depression of the amino acid level was noted among these dogs as well as in the previous group (cf. Figure 11 with Figures 1 and 2).

Comment: It is concluded that non-toxic doses of pyruvate are cleared by the dog in shock somewhat less well than in the normal before transfusion and about as well as normal after transfusion, whether reversible or irreversible to transfusion. These results suggest that the slightly decreased clearance in the pre-transfusion stages is due to decreased blood flow, particularly through the liver, rather than to any specific damage to the enzyme systems involved, for if damage to enzyme systems were responsible for defective clearance, one would not expect so prompt a recovery of clearance function following transfusion, and one would expect a disparity between the results in irreversible and reversible shock.

\section{DISCUSSION}

It has been demonstrated in traumatized rats (13) that the accumulation in the blood of lactic acid, inorganic phosphate, and phosphopyruvic acid occurs simultaneously with a progressive exhaustion of energy reservoirs in tissues (14), particularly in liver and brain. A correlation has been said to exist between survival and the magnitude of the original rise in the blood level of these intermediary metabolites as well as in the speed of their return to normal values (13). If the blood concentrations of these metabolites reflect the extent of the biochemical lesion in the tissues, a study of their behavior in response to therapeutic transfusion in hemorrhagic shock in dogs might provide a key to the nature of the irreversible lesion and at the same time demonstrate whether they are essential components of the lethal process or 
merely concurrent phenomena of secondary importance.

Russell et al (7) concluded that since eviscerated (liverless) rats do not show elevations in the $\mathrm{L} / \mathrm{P}$ ratio comparable to those in non-eviscerated rats or eviscerated shocked rats, peripheral anoxia rather than liver failure is largely responsible for the increase in the $\mathrm{L} / \mathrm{P}$ ratio. Dogs in hemorrhagic shock show a progressive increase in lactate and a fall in glucose in the venous as compared to the arterial blood, suggesting an increased conversion of glucose to lactate caused by the anoxia of peripheral vascular failure (15). Our experiments are consistent with these conclusions. They indicate further that the actual level of blood lactate achieved is controlled by a factor other than the mere rate of production of lactic acid.

The rise in the $\mathrm{L} / \mathrm{P}$ ratio in hemorrhagic shock results from the predominance of anaerobic over aerobic carbohydrate metabolism, especially in muscle (16), in the presence of peripheral circulatory failure. In this situation energy is derived largely from glycolysis, whose end product is lactic acid. This is much less efficient than aerobic oxidation since 8 to 14 times as much substrate is required to yield the same amount of energy (17).

In spite of the rise in lactic and pyruvic acids and the increase in the $\mathrm{L} / \mathrm{P}$ ratio in shock, additional loads of these acids and of glucose are metabolized almost as well as in the normal state, ${ }^{8}$ regardless of the severity of the shock state or the response to transfusion. The return of the $\mathrm{L} / \mathrm{P}$ ratio to normal following transfusion indicates a return to aerobic metabolism of carbohydrate. Since this is the case whether or not the transfusion is therapeutically effective, it appears that even a temporary improvement of blood flow is capable of restoring the normal rate of carbohydrate breakdown but is not capable of restoring the integrity of the factor responsible for maintenance of normal function of the peripheral vascular system. It follows that the distortion in carbohydrate metabolism, as reflected by the blood changes studied, is probably not a primary factor in peripheral vascular failure. If it were otherwise, death from ordinarily fatal shock would not be prevented by liver perfusion, during which the distortion of

\footnotetext{
8 We do not assume that the disappearance of these metabolites from the blood in shock is necessarily achieved by the mechanism prevailing in the normal state.
}

carbohydrate metabolism is of the same kind and magnitude as is seen in shocked dogs not perfused or perfused via another route (4). To be sure, our blood analytical data may not disclose persisting metabolic abnormalities in certain vital tissues, whose function, therefore, continues to be adversely affected; for example, the brain stem may suffer from the decrease in oxygen supply (14) in spite of the apparently normal enzymatic behavior suggested by the blood findings. But there is no evidence to indicate that in the circumstances of our experiments any organ apart from the liver is of critical importance with respect to the collapse of the peripheral vascular system in shock, since such organs, including the brain, respond well to transfusion after exposure to a degree of hypotension and hypoxia which the liver cannot tolerate. Since the liver has been shown to be the critical organ with respect to the integrity of the peripheral vascular system in shock, the damage it suffers involves at least another category than that of carbohydrate oxidation.

\section{SUMMARY}

1. Morphinized dogs bled into shock showed rapid elevation of blood lactic acid, pyruvic acid, amino acid nitrogen, and the lactic/pyruvic acid ratio.

2. A rapid return toward normal of blood lactic and pyruvic acids and the lactic/pyruvic acid ratio followed transfusion, whether or not the transfusion was curative.

3. The blood amino acid nitrogen remained elevated following transfusion.

4. A continuous drip of epinephrin produced elevations in blood glucose, but much smaller elevations in blood lactic and pyruvic acids and in the lactic/pyruvic acid ratios than occur in hemorrhagic shock.

5. In adrenalectomized dogs, whose tolerance to hemorrhage was poor, the blood levels of lactic and pyruvic acid and the lactic/pyruvic acid ratio increased even though the blood glucose level fell.

6. Arterial blood under oil kept at body temperature showed a slight increase in lactic acid and the lactic/pyruvic acid ratio.

7. The disappearance of injected glucose from the blood was poor or nil during hemorrhagic shock. Following transfusion (even in irreversible shock) this clearance was normal. 
8. The clearance of injected lactate from the blood during shock was normal. The restoration of the elevated lactic acid level to normal by transfusion is such as to mask completely the expected increase in level from injected lactate.

9. Clearance of injected lactate in normal dogs was not altered by acidosis induced by the intravenous administration of minéral acid.

10. In normal dogs the pyruvic acid level in the blood returned to normal within 45 minutes following the injection of pyruvate.

11. The elevated lactic/pyruvic acid ratio in shock was only temporarily altered by injected pyruvate.

12. Dogs in irreversible hemorrhagic shock showed disappearance rates for injected pyruvate similar to the normal in the post-transfusion phase of shock but somewhat poorer in the hypotensive pre-transfusion phase of shock, when doses of pyruvic acid that were not toxic were used (under 0.1 gram per kgm.).

\section{CONCLUSIONS}

It is concluded that while hemorrhagic shock may interfere with the functional efficiency of the enzyme systems involved in carbohydrate metabolism, the integrity of the enzyme systems involved in lactic and pyruvic acid metabolism is not seriously damaged, because they show a rapid return to normal function following transfusion. The occasionally lowered tolerance to injected glucose and pyruvic acid noted during the oligemic phase of hemorrhagic shock is due to deficient velocity and volume of blood flow through tissues. The accumulation of these metabolites in the blood results from the combined effects of poor blood flow and an increased rate of production in anoxic tissues.

The development of irreversibility to transfusion in hemorrhagic shock is not due to inability of the liver to metabolize lactic and pyruvic acids. Abnormalities in carbohydrate metabolism, so far as they are reflected in the elevations of lactic and pyruvic acids, are not related to the development of irreversibility to transfusion.

Acknowledgment is due the following for technical assistance: Miss Martha Goldberg, Miss Gertrude Weinberger, Mrs. R. B. Griffin, Miss Dorothy Kaufman, Miss Greta Landwehr, and Mr. Thomas W. Barnett.

\section{BIBLIOGRAPHY}

1. Blalock, A., and Levy, S. E., Effect of hemorrhage, intestinal trauma and histamine on partition of the blood stream. Am. J. Physiol., 1937, 118, 734.

2. Wiggers, C. J., Opdyke, D. F., and Johnson, J. R., Portal pressure gradients under experimental conditions, including hemorrhagic shock. Am. J. Physiol., 1946, 146, 192.

3. Goldberg, M., and Fine, J., Unpublished observations.

4. Frank, H. A., Seligman, A. M., and Fine, J., Traumatic shock. XIII. The prevention of irreversibility in hemorrhagic shock by vivi-perfusion of the liver. J. Clin. Invest., 1946, 25, 22.

5. Seligman, A. M., Frank, H. A., and Fine, J., Traumatic shock. XIV. The successful treatment of hemorrhagic shock irreversible to transfusion by vivi-perfusion of the liver. J. Clin. Invest., 1947, 26, 530.

6. Engel, F. L., Winton, M. G., and Long, C. N. H., Biochemical studies on shock. I. The metabolism of amino acids and carbohydrate during hemorrhagic shock in the rat. J. Exper. Med., 1943, 77, 397.

7. Russell, J. A., Long, C. N. H., and Engel, F. L., Biochemical studies on shock. II. The role of the peripheral tissues in the metabolism of protein and carbohydrate during hemorrhagic shock in the rat. J. Exper. Med., 1944, 79, 1.

8. Stotz, E., and Bessey, O. A., The blood lactate-pyruvate relation and its use in experimental thiamine deficiency in pigeons. J. Biol. Chem., 1942, 143, 625.

9. Bueding, E., and Wortis, H., The stabilization and determination of pyruvic acid in blood. J. Biol. Chem., 1940, 133, 585.

10. Barker, S. B., and Summerson, W. H., Colorimetric determination of lactic acid in biological material. J. Biol. Chem., 1941, 138, 535.

11. Frame, E. G., Russell, J. A., and Wilhelmi, A. E., Colorimetric estimation of amino nitrogen in blood. J. Biol. Chem., 1943, 149, 255.

12. Folin, O., Two revised copper methods for blood sugar determinations. J. Biol. Chem., 1929, 82, 83.

13. McShan, W. H., Potter, Van R., Goldman, A., Shipley, E. G., and Meyer, R. K., Biological energy transformations during shock as shown by blood chemistry. Am. J. Physiol., 1945, 145, 93.

14. Le Page, G. A., Biological energy transformations during shock as shown by tissue analyses. Am. J. Physiol., 1946, 146, 267.

15. Beatty, C. H., The effect of hemorrhage on the lactate/pyruvate ratio and arterial-venous differences in glucose and lactate. Am. J. Physiol., 1945, 143, 579.

16. Friedemann, T. E., and Barborka, C. J., The significance of the ratio of lactic to pyruvic acid in the blood after exercise. J. Biol. Chem., 1941, 141, 993.

17. Lipmann, F., A Symposium on Respiratory Enzymes. Univ. of Wisconsin Press, Madison, 1942. 